\title{
A Study on the Implication of Modified Joint Configuration in Friction Stir Welding
}

\author{
Uttam Acharya ${ }^{1,2 *}$ (D), Tanmoy Medhi ${ }^{1}$, Durjyodhan Sethi ${ }^{1}$, Smrity Choudhury $^{1}$, Abhijit Banik ${ }^{1}$ (D), Subhash Chandra Saha ${ }^{1}$, Barnik Saha Roy ${ }^{1}$ \\ ${ }^{1}$ National Institute Technology Agartala, Department of Mechanical Engineering, Tripura, India \\ ${ }^{2}$ Assistant Professor, Mechanical Engineering, Amity University Kolkata, Kolkata, India
}

Como citar: Acharya U, Medhi T, Sethi D, Choudhury S, Banik A, Saha SC, et al. A study on the implication of modified joint configuration in Friction stir welding. Soldagem \& Inspeção. 2021;26:e2606. https://doi.org/10.1590/0104-9224/SI26.07

\begin{abstract}
The current investigation is a preliminary approach proposing the feasibility of a modified joint configuration namely double-butt-lap (DBL) in the field of friction stir welding (FSW). The main scope of adopting this kind of joint configuration is to essentially eliminate the irregularities in material flow and defects (root gap, kissing bond) that are observed while joining by using the commonly followed simple square butt joint configuration (SSB) technique. Two different geometries of the joint configuration are fabricated on $6 \mathrm{~mm}$ thick AA6061-T6 plates. FSW is carried out at a parametric combination of $1100 \mathrm{rpm}, 75 \mathrm{~mm} / \mathrm{min}$ and $1.5^{\circ}$ tilt angle. The comparison of the macrographs of DBL with SSB reveals a quite distinct cross-sectional macrostructure of DBL from SSB in terms of material flow in the nugget zone (NZ). Sharp material flow lines without any macro defects are observed in the case of DBL 2 . Mechanical test analysis reveals remarkable enhancement in the mechanical properties of some joint configuration of DBL over SSB. The current research work may act as a foundation for future research work in the utility of such configurations in the diverse field of FSW.
\end{abstract}

Key-words: Friction stir welding, joint configuration; Macrostructure; Weld defects; Microstructure; Mechanical properties.

\section{Introduction}

Friction stir welding (FSW) is an innovative and reliable solid-state joining process, pioneered by The Welding Institute (TWI) in 1991 [1,2]. The FSW technique has some extra advantages over fusion welding in terms of its applicability. It eliminates various solidification defects associated with the fusion welding of classic lightweight material like aluminum and its alloy as well as other categories of non-ferrous material by processing in solid-state conditions $[3,4]$. Particularly aluminum and its alloys are widely used in aviation, automobiles, railways, construction and electrical industries due to their high strength to weight ratio, electrical conductivity and corrosion resistance properties [5,6].

This has urged many researchers to observe various aspects of FSW while joining aluminum alloys. The significant parameters that affect the aspects of FSW are rotational speed, traverse speed, forces involved and tool tilt angle [7,8]. But lately, the prospect of adopting a joint configuration that is unusual from the existing basic joint configurations (simple square butt (SSB) and lap configurations) is under focus in the current research scenario. Such modifications in joint configurations are needed to be explored to yield strong and defect-free joints that will be beneficial over welds carried out by adopting basic joint configurations. A modified butt joint configuration was adopted for joining Ti-6Al-4V alloy to Al-6Mg in order to obtain a high quality joint, avoid melting of aluminum and reduce tool shoulder attrition [9]. The result shows good formability of the joint without any weld defects. Also, a significant strength attributing up to $92 \%$ of parent alloy strength was observed. A special design of butt joint configuration was utilized to join Ti-6Al-4V titanium alloy and 5A06 aluminum alloy [10]. Joint macrostructures showed better formability as well as material flow characteristics that efficiently improved the strength of the joints. The influence of a tooth-shaped joint configuration technique was reported for joining 6061aluminum alloy and commercially pure copper [11]. Improved surface morphology and material flow patterns in the form of lamellar flow were detected. A reduced brittle fracture region was observed which led to the achievement of a ductile joint. The new joint geometry was adopted to join AA 6061 and steel by preparing a steel sheet with contoured geometry and an aluminum sheet with a normal straight edge [12]. The selection of such geometry yielded successful joints by overcoming the effects due to distortion while joining thin sheets. The analysis of joining AA6063-T6 by FSW in scarf joint configuration was reported by Goel et.al [13].

From the existing literature, it has been observed that modifications in joint configuration techniques are significant in the case of dissimilar material joining primarily concerning formability and enhancement of strength. The limitation of the above literature are, i) these are specifically for dissimilar metal joining, ii) they cannot be implemented for joining similar thickness plates, or, iii) the configurations are comparatively complex and are not easy to prepare. This motivates the

Recebido: 15 Set., 2020. Aceito: 21 Jan., 2021.

*E-mail: uttamacharya1989@gmail.com

This is an Open Access article distributed under the terms of the Creative Commons Attribution Non-Commercial License which permits unrestricted noncommercial use, distribution, and reproduction in any medium provided the original work is properly cited. 
development of such a weld joint configuration that can easily overcome all these limitations from the previous research work and can efficiently serve the purpose in the field of FSW. Additionally, there is a need to modify the joint configuration to enhance the strength of joints of age-hardened materials produced by FSW. It is has been repeatedly observed in the joining of any type of material with conventional SSB type joint configuration through FSW that a certain portion of material beneath the tool pin tip in the weld joint line remains untouched by the tool pin and remains virgin and creates a root gap defect in the joint portion. Further, the Remnant layer (Kissing bond) is also one of the most observe defects in FSW which started from the extreme weld bead surface and ends at the root gap by propagating through the nugget zone. Sometimes these defects jointly originate in the structure and become responsible for the easy failure of the FSWed samples even though the welding is formed at an adequate parametric combination for facilitating the optimum amount of heat input to soften the material. Hence in this study, a modified joint configuration technique termed as 'double butt-lap' (DBL) configuration is adopted for joining AA6061-T6 alloy. The current research states a preliminary analysis of the formability and strength of the joints produced in DBL configuration and may act as a foundation to reveal the capability of this kind of configuration in the area of FSW. Moreover, the joining line of the abutting edge comes in direct contact with the tool pin. Any modification in joining line configuration may also affect the tool-workpiece interface (as the position of joint in advancing and retreating side changes) due to differential heat and deformation characteristics of FSW. The torque and force responses for such joint modifications have not been studied elaborately. Hence, an attempt is also made to measure the torque and force responses which may assist in further analysis of such joint configuration behavior. The effect of the joint configuration on the material flow is analyzed from the macrostructure. The feasibility of the DBL joint configuration over SSB type in FSW is justified by conducting various mechanical testing on the structure. It is supposed that this study will be well understood by the readers and will open a new scope for further research work on the weld joint line configuration.

\section{Introduction to the double-butt-lap joint configuration}

The modified joint configuration is designed to facilitate higher faying surface area in the weld nugget zone compare to conventional SSB joint configuration in FSW. DBL joint geometry is simple and can be easily prepared similarly to SSB in a conventional milling machine. The schematic representation of the DBL joint configuration is shown in Figure 1 . The geometry of the modified joint configuration is a combination of two SSB [upper butt (UB) and lower butt (LB)] and an overlap, where the weld centreline (or tool axis) passes longitudinally through the middle of the overlap. The width of the overlap is kept smaller than the tool pin tip diameter aimed to facilitate the total joint configuration area under the active and direct influence of pin influenced region so that the chances for the formation of root gap defect can be ignored. The ratio of the height of the butt (UB: LB) may depend on the type of material to be welded, the thickness of the plates, the type of tool pin to be used for the welding and previous experience on FSW of a particular material.

\section{AS: Advancing Side; RS: Retreating Side; P1: Plate on AS; P2: Plate on RS UB: Upper Butt height; LB: Lower Butt height; LL: Lap/Overlap length SSB: Simple square butt joint configuration; DBL: Double-butt-lapjoint configuration.}

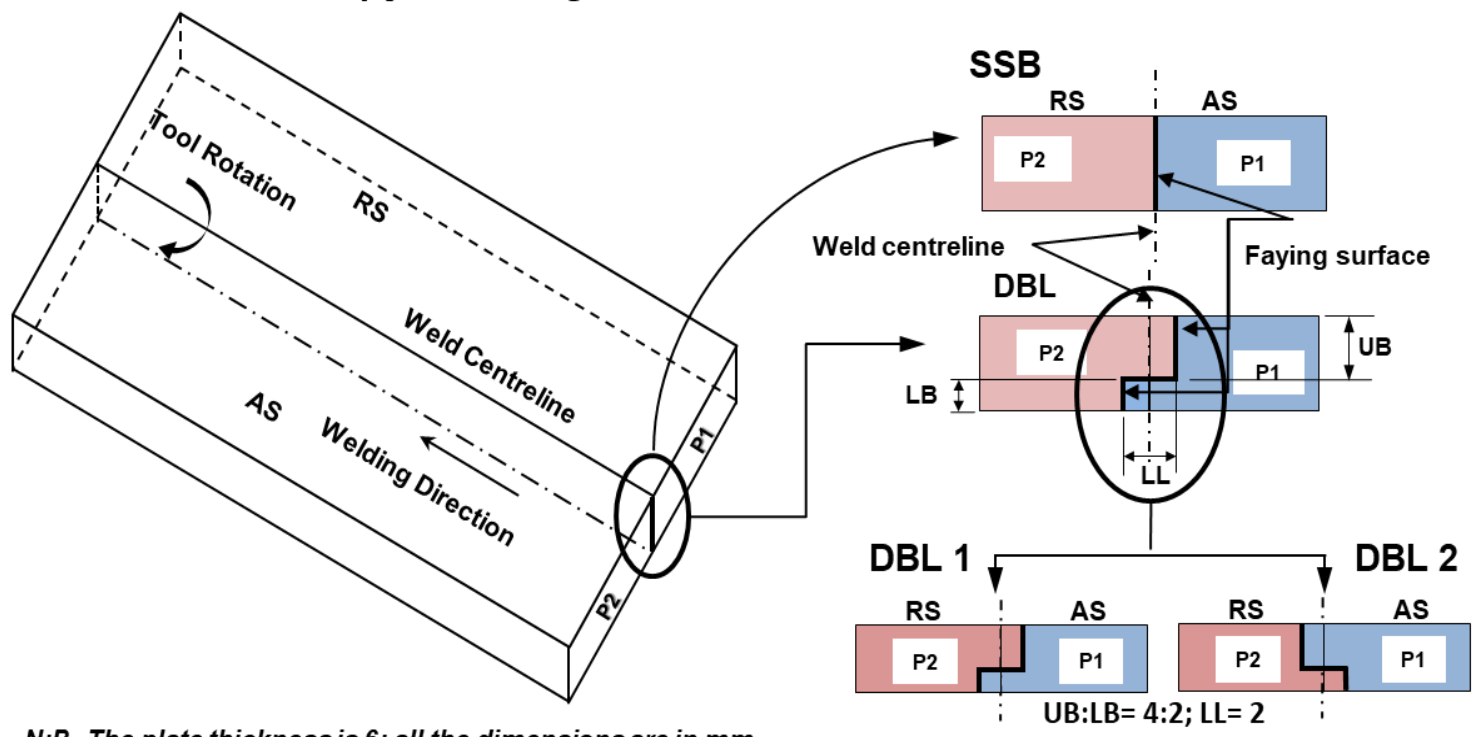

$\mathrm{N}: \mathrm{B}-$ The plate thickness is 6; all the dimensions are in $\mathrm{mm}$

Figure 1. Schematic representation of SSB and DBL joint configuration. 


\section{Experimental Details}

The initial experiments for modified DBL joint configuration are investigated on $6 \mathrm{~mm}$ thick AA6061-T6 plates. The welding is performed in a dedicated 3Ton FSW setup. A taper threaded tool made of $\mathrm{H}-13$ tool steel (56 HRC) with18 mm shoulder diameter and pin height of $5.7 \mathrm{~mm}$ having bottom dia. of $6 \mathrm{~mm}$ and tip dia. of $3 \mathrm{~mm}$ is used for the welding. The process parameters for the final welding are selected following a trial and error method to attain a defect less joint. It was observed that sound welding was achieved at higher rpm and a moderate tilt angle of 1.5 thereby assuring proper placement of the plates at the given configuration which otherwise gets displaced due to pulling action at higher tilt angles. All the welding is performed with a constant tool rotational speed (TRS) of $1100 \mathrm{rpm}$, tool traverse speed (TTS) of $75 \mathrm{~mm} / \mathrm{min}$ and tool tilt angle (TTA) of 1.5 to make the comparison simple. The particular parametric combination is chosen from the previous experience of welding on $6 \mathrm{~mm}$ thick AA6061 plates having an SSB joint configuration that shows the better mechanical property. Three sets of welding of each type having $100 \mathrm{~mm}$ length are performed in ideal condition to check the consistency of parameter for different joint configurations at a fixed dwelling time of $5 \mathrm{~s}$ with a plunge rate of $20 \mathrm{~mm} / \mathrm{min}$ and $0.1 \mathrm{~mm}$ shoulder plunge depth. The welding is compared in terms of the formation of the weld structure (material flow) and mechanical property aimed to check the feasibility of DBL type joint configuration in FSW to conventional SSB type.

To fix the proper combination of shape and size of DBL joint configuration several trials runs with various combinations of UB: LB ratio $(1: 2 ; 1: 1 ; 2: 1)$ with $L L$ of $2 \mathrm{~mm}$ is conducted. The fixed $L L$ of $2 \mathrm{~mm}$ is considered so that the whole joint configuration can bring under the active influence of a $3 \mathrm{~mm}$ tool pin tip diameter. Out of the various combination of UB: LB, 2:1 combination shows the better mechanical property in the preliminary experiments. In the current study two types of modified DBL joint configurations with UB: LB of 2:1 and LL of $2 \mathrm{~mm}$ are considered over conventional SSB type joint configuration (Figure1). For the two DBL joint configurations, the UB length is kept $4 \mathrm{~mm}$ for one and the other is set to $2 \mathrm{~mm}$. The only difference between DBL 1 and DBL 2 is that they are kept mirrors to each other that is the butting positions are interchanged between them (Figure 1). The mirror designs of configuration are considered in the study are aimed to validate and compare the DBL configurations (DBL 1 or DBL 2) in terms of material flow. The configurations are prepared in milling by maintaining their shape and size and are cleaned by ethanol before welding.

The temperature in both AS and RS of the plate during welding is measured using a K-type thermocouple attached to a data acquisition system, which is placed $7 \mathrm{~mm}$ away from the weld centreline, at a depth of $3 \mathrm{~mm}$. The different forces and torque involved in the process are measured and retrieved by a strain gauge based load cell, controlled through a NI LabView software-based PLC system. The macroscopic samples are taken out from the same region for each welding with different weld joint configurations where the torque and force are comparatively in stable condition. The samples are then finely polished with different grades of emery paper, alumina and colloidal silica and etched with Keller's reagent prior to investigation under macroscope. Each mechanical tests are conducted three times for better accuracy. Tensile testing was performed to obtain the ultimate tensile strength (UTS) and \% elongation at a strain rate of $0.5 \mathrm{~mm} / \mathrm{min}$ in INSTRON 8801 machine as per the ASTM E8 standard. The bend tests are performed to find the mechanical resistance of welded samples under bending stresses (root bend). Tests are conducted as per ASTM code and NP EN 910 standard with specimens of dimension $140 \times 20 \times 6 \mathrm{~mm}$ and strain rate of $0.5 \mathrm{~mm} / \mathrm{min}$.

\section{Results and Discussion}

This part is focused to support the feasibility and compatibility of modified DBL over conventional SSB joint configuration in the field of FSW. As it is a preliminary investigation to introduce modified (DB) joint configuration in FSW, so to keep the study simple the results are limited to the analysis of material movement and flow in the weld zone structure and various mechanical properties of the joint for different joint configurations are interpreted to support the study.

\subsection{Analysis of material movement and flow}

Since the process discussed here is a means of welding, the amount of heat input is always a concern and affects material deformation and flow. A deviation from the required amount of heat may bring defects in the formation of weld besides the deformation imparted by the tool. The extent of resistance offered by the material in terms of force and torque to the tool depends on the softness of the material beneath the tool shoulder and is governed by the heat input to a large extent. Hence an attempt is made to analyze the thermal cycles involved in the weld of each joint configuration which may assist for further analysis of torque and forces and thereby the material movement.

\subsubsection{Study of time-temperature plots}

Figure 2 depicts the variation of time-temperature weld thermal plots showing peak temperature in AS and RS of the welding for different joint configurations at similar parametric combinations. The temperature is measured at a point coordinated at the middle of the weld run (50 mm away from weld start), $7 \mathrm{~mm}$ away from the weld centreline and at a depth of $3 \mathrm{~mm}$ from the weld top surface. The peak temperature measured at the respective position for SSB, DBL 1 and DBL 2 in AS 
is $477.6{ }^{\circ} \mathrm{C}, 445.5^{\circ} \mathrm{C}$ and $489.17^{\circ} \mathrm{C}$, whereas in $\mathrm{RS}$ it is $448{ }^{\circ} \mathrm{C}, 462.9^{\circ} \mathrm{C}$ and $445.9{ }^{\circ} \mathrm{C}$ respectively. It can be observed from the figure that the nature of the time-temperature plots for DBL configurations is very much similar to that of the SSB. However, the difference in the values of peak temperatures can be observed even though all the welding is conducted in similar conditions. This finding reflects the effect of joint configuration on effective heat input available to perform the welding. Also, the variation of peak temperature lies between the AS and RS of the welding. This variation of peak temperature in AS and RS of the welding with SSB joint configuration is also reported by different authors in their research work [14,15]. The higher peak temperature in RS compared to AS in DBL1 configuration may be due to the extruded material of RS plate in shoulder influenced region beyond the weld centreline. This facilitates higher deformation of the RS plate material and created differences in the amount of frictional heat sensed by the plate beneath the shoulder and thus resulted in higher temperatures in the RS compared to AS. On the other side, for DBL2 a much higher temperature in AS compared to RS is measured which can be attributed to the case vice-versa to the DBL1.
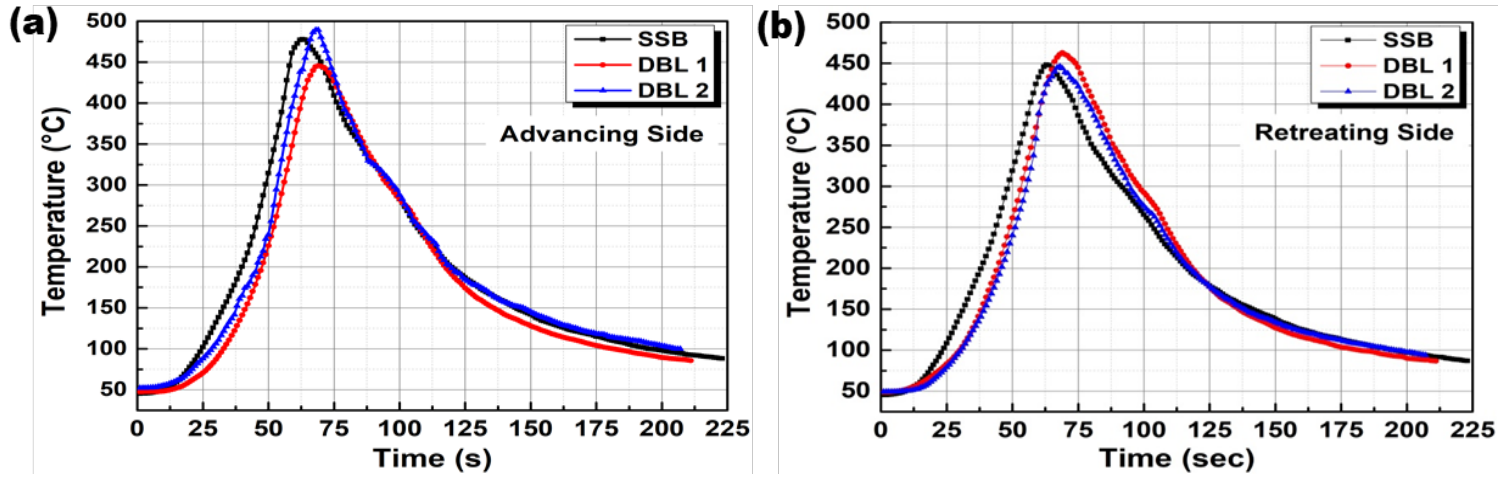

Figure 2. Weld thermal cycle for different joint configuration (a) Advancing side, (b) Retreating side.

\subsubsection{Study of force and torque}

Figure 3 shows the comparison of force and torque generated during welding employed with different joint configurations. The forces and torque in FSW are experienced by the tool and their intensity depends on the extent of deformation of the material beneath the shoulder and in the vicinity of the tool pin [16]. The extent of deformation of material at the weld zone depends on the amount of heat evolved in the process by varying the process parameters or by any other change in a tool or the workpiece material. The plots for the different joint configurations shown in the figure show sharp changes in the pattern although the process parameters remain the same for all the cases. So, these indicate a certain effect of joint configuration.

Figure 3a. shows the variation of force experienced by the tool pin [7] due to the resistance offered by the workpiece material (X-force) in the course of welding. The extent of fluctuations of $X$-force for different joint configurations is characterized in terms of the measure of its width. It can be seen from the graph that, for an initial period of $10 \mathrm{~s}$ the $\mathrm{X}$-force increases for the welding with SSB. This may be due to the higher resistance offered by the material owing to the lack of heat at the leading side of the tool. This is followed by a decrease may be due to the increase in heat input. This is due to the frictional heating beneath the tool along with preheating of the material in the leading edge facilitating softer material in the vicinity of the tool pin. This type of increase and decrease in X-force can be observed throughout the plot due to a similar reason. It can be also observed that the extent of fluctuation in this case gradually increases up to $35 \mathrm{~s}$ and then proceeds roughly uniformly. In FSW with SSB joint configuration, the tool axis and the joint line merges and thus facilitates an asymmetric action of the tool in both AS and RS of the plates. Typically, the AS plate exhibit a higher amount of heat input than the RS plate due to the different modes of material deformation in AS [7]. The gradual increase or decrease in the extent of Xforce fluctuation as shown may also be related to this statement. On the other hand, in the case of the welding with DBL 1 , it can be observed that the X-force decreases for the initial $10 \mathrm{~s}$ and then gradually increases for the rest of the welding. This is consistent with the explanation given for SSB type for such decrease and increase. In this case, as the tool pin largely moves through the RS material, so it can be said that the material under the shoulder and near the tool pin deforms the material that has a higher heat input in it. Additionally, a particular amount of softer material also comes in this region from the AS plate. So, it can be understood that the material which is being deformed by the pin in this condition is softer and as a result, it will create lower resistance in the tool movement. Thus this condition facilitates the overall decrease in X-force compared to SSB type. The extent of fluctuation, in this case, is less than the SSB configured joint may be due to the same reason. The welding with DBL 2 shows a stable fluctuation of $X$-force throughout the weld run. It indicates that a constant amount of resistance has been experienced by the tool provided by the plastically deformed material. This indicates more uniform material flow throughout the weld run compared to the other two conditions. 
Figure $3 \mathrm{~b}$. shows the variation and comparison of the downward force exerted by the tool (Z-force) to consolidate the plastically deformed material in the weld zone. At the very initial stage, all the welding shows a sudden increase with an immediate decrease in the value of Z-force. At the initial stage due to less availability of heat, an extra amount of force is exerted by the plates in an upward direction and material is less deformed and tries to displace it from its position. To overcome this particular situation an extra amount of reaction force has been exerted by the tool on the plate to keep it in its position. This increases the force at the initial stage and once this condition finishes due to the availability of heat the Z-force immediately reduces. The welding with SSB shows a higher amount of Z-force with an uncertain variation in the fluctuations throughout the run compared to the welding with the other two configurations. Whereas, DBL 1 configured joint shows a gradual increase, while DBL 2 configured joint shows comparatively stable and less variation in the fluctuation of Z-force.
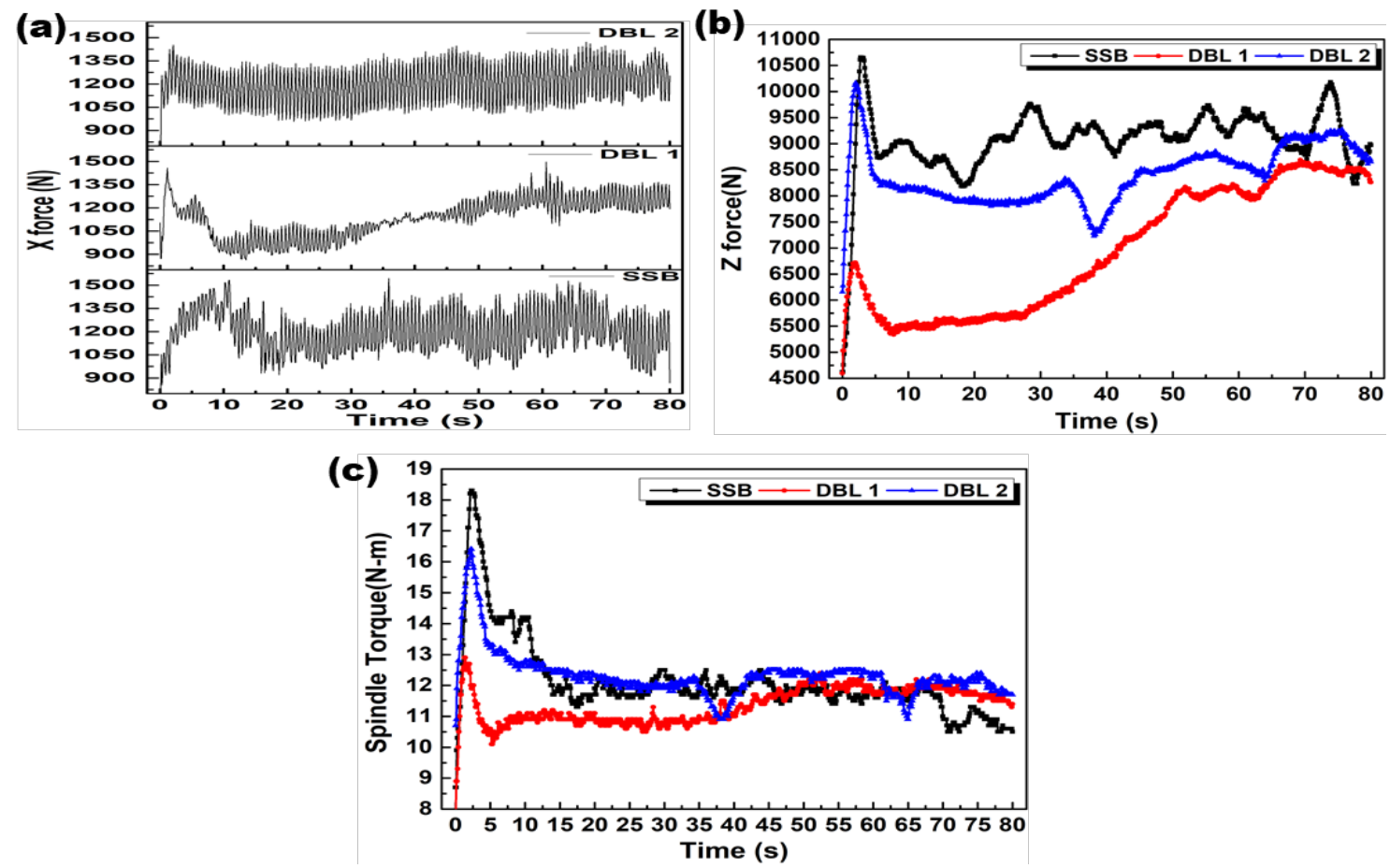

Figure 3. Comparison of force and torque of welding for different weld joint configuration, (a) Comparison of X-force; (b) Comparison of Zforce; (a) Comparison of spindle torque.

Figure 3c. shows the response of the material to resists the angular deformation (spindle torque) due to the rotation of the tool. The variations of spindle torque for the welding at different weld joint configurations are very much consistent with that of X-force and Z-force and the pattern of plots is similar to that of Z-force distribution.

\subsection{Surface appearance and macrostructural analysis}

Figure 4 represents the morphology of the weld bead with the respective macrostructure of joints for different joint configurations. The force and torque involved in the welding depend on the deformation of the material which interns depend on the placement of the plates beneath the shoulder. The formation of different types of weld structures for varying joint configuration is the direct reflection of varying material flow that may occur due to the variation of joint configuration as a distinct effect on the torque and forces can be observed. for various weld joint configurations, The weld bead appeared to be defect-free throughout the welding for all the configurations. The macrostructural images revealed good formability without any defects. The black line indicates the weld centreline and the red line indicates the joint line of the faying surfaces in DBL configuration (Figure 4).

To analyze and understand the material flow behavior more clearly for different joint configurations, separate welding has been conducted for all the weld joint configuration by inserting copper ( $\mathrm{Cu}$ ) foil of $0.1 \mathrm{~mm}$ thickness between the whole faying surface of two plates (Figure 5). It is done upon the assumption that the displacement of Cu foil with respect to its original site will be directed by the movement of its adjacent material from the AS or RS plate which will ultimately help to trace the material movement (material flow) in the nugget zone (NZ) pictorially [17]. The pictorial analysis in the macrostructure formed for different joint configurations can provide more insights in terms of differences in material flow for different joint configurations. 


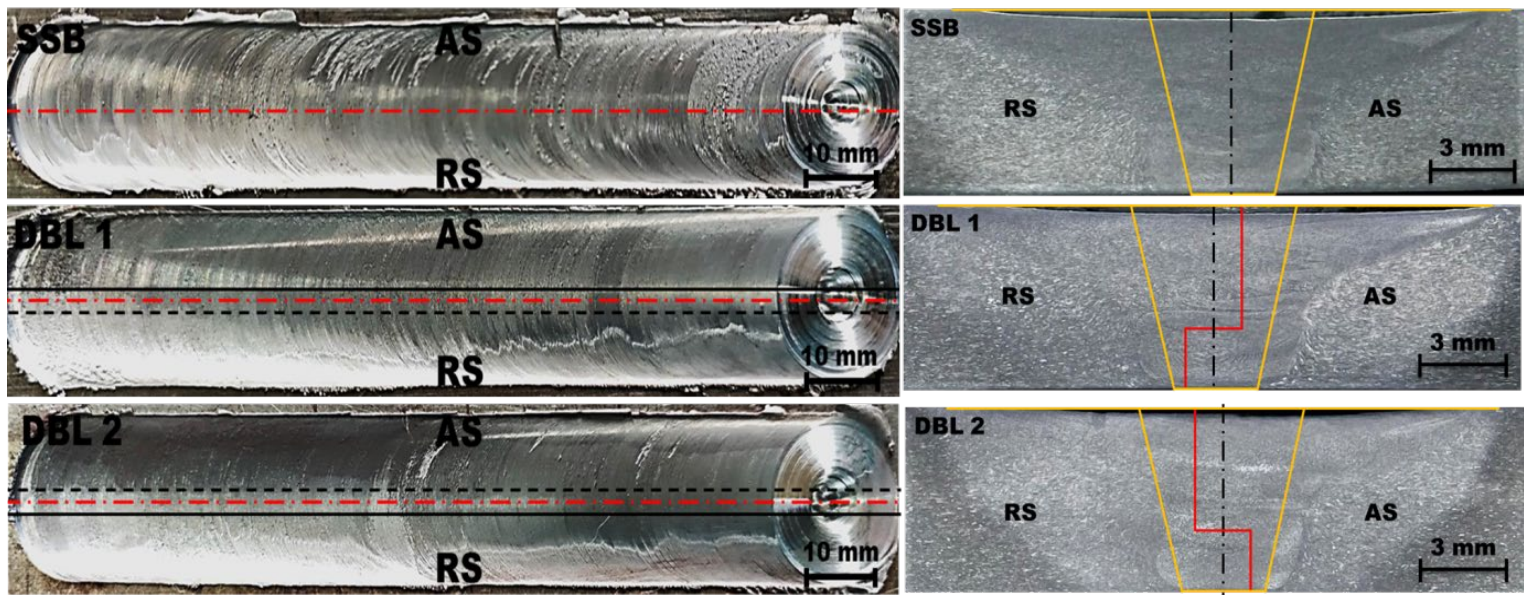

Figure 4. Weld bead appearance and respective macrostructure of joints formed with different joint line configuration.

In Figure 5, all the zones are distinct but the interface of NZ and TMAZ is more prominent in the AS. DBL1 and DBL2 show an adequate material flow under the shoulder influenced zone extending to the pin influenced zone of the weld nugget. Whereas, clear differences in the distribution and way of deformation of $\mathrm{Cu}$ in the weld geometry formed with different joint configurations can be observed. The differences in deformation behavior and displacement of $\mathrm{Cu}$ foil are due to variation in the placement of $\mathrm{Cu}$ foil between the differently oriented faying surfaces of two plates in the current study as all other condition remains the same for all the welding. The macrostructure of SSB shows that the Cu foil, particularly at the shoulder, influenced region shifts towards the AS by completely vacating from its actual position in the weld centreline. In DBL 1 configuration the UB is offset by $1 \mathrm{~mm}$ from the weld centreline. Similar to this, in DBL 2 the UB is offset by $1 \mathrm{~mm}$ in RS from the weld centreline. In both cases, it can be observed that the material flow in the shoulder influenced region is very much similar to that of SSB type, where the material tends to deform from RS to the AS side. This evidence that the nature of the deformation of plasticized material in the shoulder influenced region is towards AS from RS of the plate. It is very likely in FSW that an optimum amount of material should be transported from one side to another to attain a sound weld joint [18]. It can be observed from the macrostructure that in the case of DBL 2 that comparatively higher amount of material has been transported on either side.

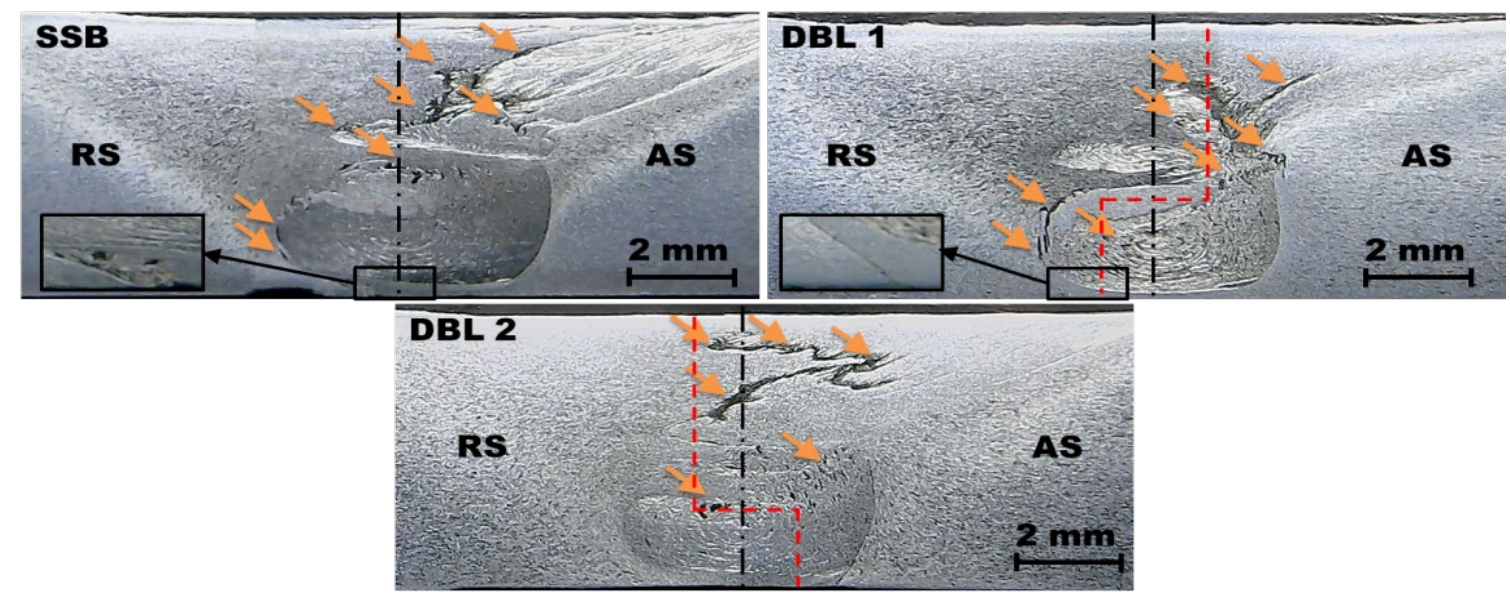

Figure 5. Macrostructure of the joints showing different types of material flow as an effect of variation in the joint configuration.

The appearance of the onion ring at the pin influenced region suggests good material mixing at the bottom region. Additionally, it can also be observed that the $\mathrm{Cu}$ foil is distributed in particle form in all the welding may be due to the breaking of $\mathrm{Cu}$ foil because of the vigorous stirring action of the pin. But the distribution of Cu is quite different in each case. For SSB and DBL 1, it can be observed that some amounts of Cu foil are settled in the transition zone between the NZ and TMAZ. This may be since, in FSW, the deformed material experiences an outward spinning movement from the pin surface [19]. This outward spinning movement is very prominent from AS to RS of the plate. Whereas for DBL 2 configured joint, no such accumulation of $\mathrm{Cu}$ foil can be observed in the transition zone, rather the $\mathrm{Cu}$ is distributed more uniformly throughout the pininfluenced region. This indicates that the offset of RS plate beyond the weld centreline and towards AS facilitates better mixing between the materials of AS with RS. The coalescence of plates in FSW takes place due to extrusion and stirring of the 
plasticized material at ideal heat flow conditions along the circumference of the tool pin. In SSB joint configuration the faying surfaces, weld centreline and the tool axis coincide as a result of which the material near the joint line below the pin tip surface experience a negligible amount of shear force and automatically cuts the flow of material at that portion. As a result, the material at that portion remains a virgin and may cause a root defect. The macrostructure formed with SSB and DBL 1 joint configuration in Figure 5.shows a similar type of defect may be due to the same reason as fewer amounts of RS plate material falls beneath the tool pin tip. But in DBL 2 joint configuration, the faying surfaces lie at a distance of $1 \mathrm{~mm}$ offset from the weld centreline (or the tool axis) towards the AS plate. This condition bounds the material of that portion to experience shear force and facilitates flow and results in the better coalescence of material ensuring the elimination of root defect. This phenomenon automatically minimizes the chances of the formation of KBs.

Moreover, it can be also observed that the current joint configuration consists of an overlap of $2 \mathrm{~mm}$ at a depth of $4 \mathrm{~mm}$ from the upper plate surface. This design restricts the movement of the material from the bottom portion beyond the overlap to the upper region and additionally will act as a barrier for the propagation of KB to the bottom portion even though it creates. Hence, as the tool advances during the welding, the presence of overlap will prompt a downward spiral movement of the deformed material that leads to the formation of onion rings in the bottom region of the weld nugget. At this point, the material flow in the DBL configuration differs from conventional SSB. The current study also reveals that this modified joint configuration may affect the weld zone geometry. Table 1 shows the variation of different areas and measures of the different regions for the weld geometry of the joint formed with different weld joint configurations. The data related to the macrostructure of weld geometries can be easily interpreted from the table for further comparison.

Table 1. Area analysis of different welding zones of the joints at various joint line configuration.

\begin{tabular}{cccccc} 
Sample & $\begin{array}{c}\text { Shoulder influenced } \\
\text { area }\left(\mathbf{m m}^{\mathbf{2}}\right)\end{array}$ & $\begin{array}{c}\text { Total weld area } \\
\left(\mathbf{m m}^{\mathbf{2}}\right)\end{array}$ & $\begin{array}{c}\text { Pin influenced area } \\
\left(\mathbf{m m}^{\mathbf{2}}\right)\end{array}$ & $\begin{array}{c}\text { Shoulder influenced } \\
\text { depth }(\mathbf{m m})\end{array}$ & $\begin{array}{c}\text { Pin influenced depth } \\
(\mathbf{m m})\end{array}$ \\
SSB & 55.63 & 36.98 & 18.51 & 2.75 & 3.12 \\
DBL1 & 58.32 & 37.42 & 20.75 & 2.64 & 3.22 \\
DBL2 & 54.92 & 35.83 & 18.98 & 2.7 & 3.18 \\
\hline
\end{tabular}

\subsection{Microstructural analysis}

The mechanical properties of the welded joints are highly affected by the microstructure developed and thus the microstructure of the materials needs to be analyzed in order to determine the performance of the welded joints under required conditions. The microstructure developed depends on the generation of heat and the material flow [14] which is greatly affected by the placement of the plates as discussed in the earlier section. Figure 6 represents the different zones viz. NZ, TMAZ, HAZ and BM of FSWed joints. The particular image is the micrograph of the weldzone of the joints formed with SSB configuration. The grain size is calculated with the line intercept method of the highly recrystallized zone with fine equiaxed grains. The discussion on grain size has been made in the latter part of the current section and it has been observed that the grain size of NZ along the weld centreline varies from $10.25 \mu \mathrm{m}$ to $11.12 \mu \mathrm{m}$. The TMAZ is characterized by elongated grains of a mean size equal to $33.53 \mu \mathrm{m}$. The base material is unaffected by the process heat and stirring action shows the typical rolling microstructure.

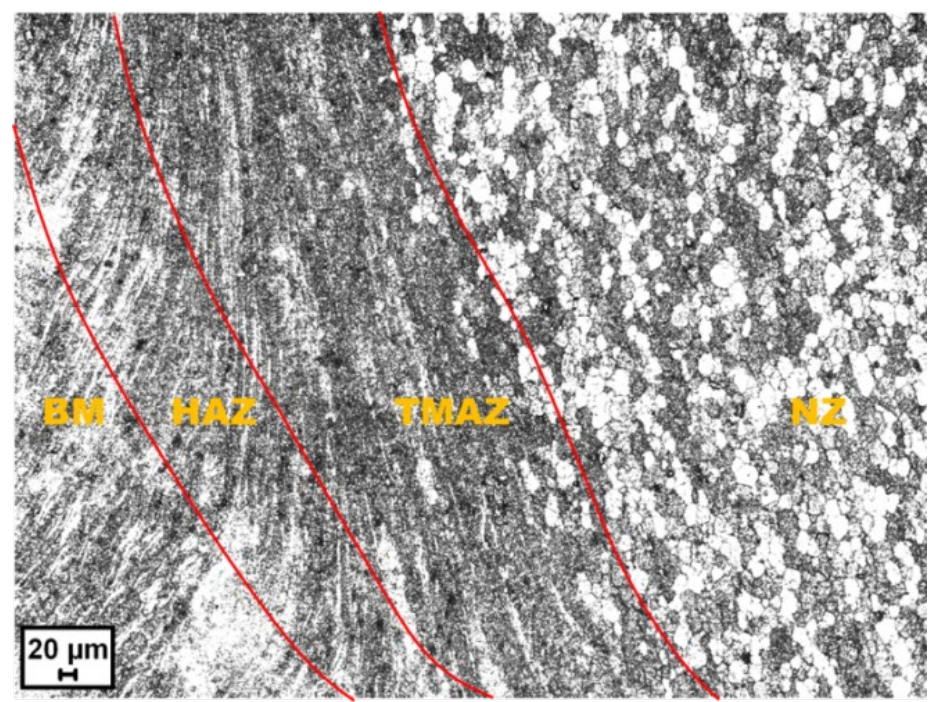

Figure 6. Typical zones of the SSB joint configuration. 
Figure 7 shows the metallographic observations for the three different joint configurations showing the distribution and displacement of $\mathrm{Cu}$ particles in NZ. The $\mathrm{Cu}$ foil inside the samples shows an adequate material mixing in the shoulder influenced region which also extends to the pin influenced zone in all the cases. The variation in distribution and displacement of $\mathrm{Cu}$ foil can easily be observed for different joint configurations and can be attributed to the variation of placement of the $\mathrm{Cu}$ foil. The formation of an onion ring implies an improved material mixing at the bottom of the NZ. The stirring action of the tool breaks the $\mathrm{Cu}$ foil into fine pieces. The distribution of fragmented $\mathrm{Cu}$ foil is different in all cases. In SSB, since the faying surfaces, weld centreline and the tool axis coincide, uniform distribution of Cu particles can be seen at the bottom of the NZ. For DBL 1 configuration, the UB is offset by $1 \mathrm{~mm}$ in AS from the weld centreline and for DBL 2 the UB is offset by $1 \mathrm{~mm}$ in RS from the weld centreline. Accumulation of Cu particles can be observed at the interface zone in the case of DBL 1 , whereas no such accumulation can be seen for DBL 2 which implies that a higher amount of material has been transported on either side in the case of DBL 2. The reason behind such uniform material transportation for DBL 2 may be attributed to the material's tendency to flow from RS to AS during welding.
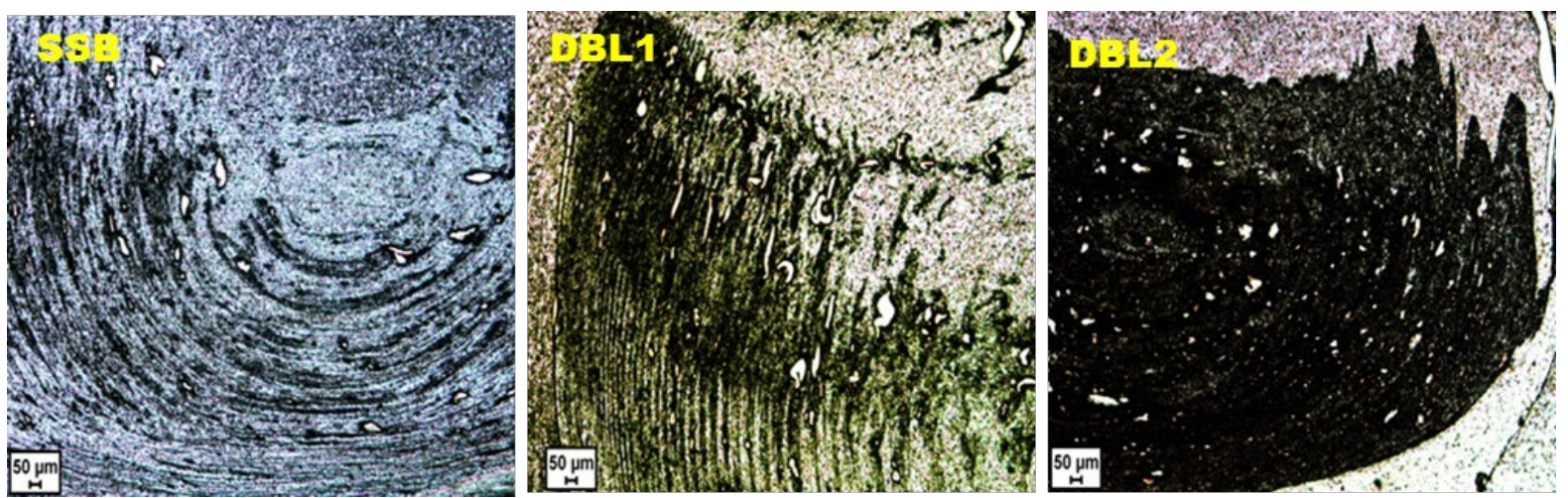

Figure 7. Metallographic observations for joint configuration showing the distribution and displacement of Cu particles.

The variation of grain sizes in three different regions within the nugget zone is measured for the varying joint configurations using ImageJ Software using the line intercept method. For each joint, 10 readings were repeated and the average was considered for comparison between the three different types of joint configuration. Figure 8 shows the metallographic images for the three different configurations in the middle of the NZ. Table 2 represents the obtained average size of grains for all joint configurations.
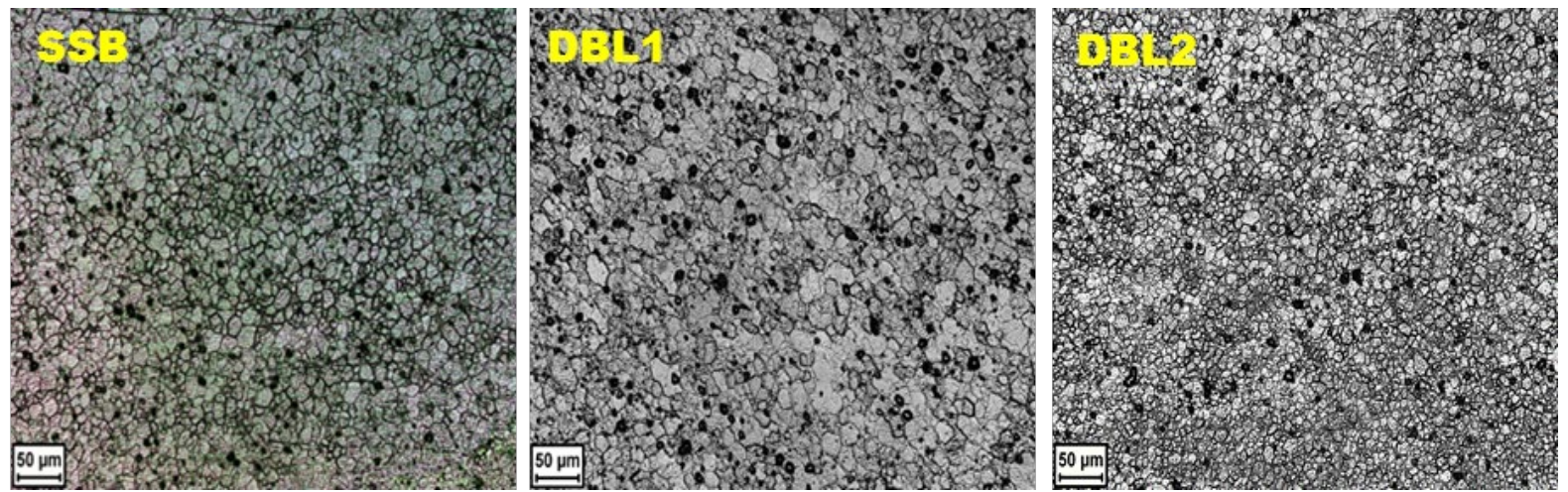

Figure 8. Metallographic images for the three different configurations in the middle of the NZ.

Table 2. Measured average grain size for the three different joint configuration.

\begin{tabular}{cccr}
\hline Zone & SSB $(\mu \mathrm{m})$ & DBL $\mathbf{1}(\boldsymbol{\mu m})$ & DBL $\mathbf{2}(\boldsymbol{\mu m})$ \\
NZ-Top & 11.12 & 11.42 & 9.70 \\
\hline NZ-Middle & 10.55 & 10.69 & 9.12 \\
\hline NZ-Bottom & 10.25 & 10.28 & 8.62 \\
\hline
\end{tabular}

From Table 2, it can be seen that the grain size measured at the top, bottom and middle of NZ are very much similar in the case of SSB and DBL 1 configuration. In SSB joint configuration the faying surfaces, weld centreline and the tool axis 
coincides, because of which a negligible amount of shear force is experienced by the material near the joint line and below the pin tip cutting the material flow at that portion. This may be the reason for the development of comparatively bigger size grains. For DBL 1 configuration, as seen from Figure 5, the accumulation of $\mathrm{Cu}$ particles in the interface zone implies a comparatively poor material mixing has occurred resulting in coarser grains. But for the DBL 2 configuration, slightly smaller grains are observed in the NZ and can be justified as better material mixing has occurred. In the case of DBL 2 , the offset of RS plate beyond the weld centreline and towards AS facilitates better mixing between the materials of AS with RS and hence more amount of material is transported on either side resulting in an improved flow of material both in shoulder and pin influenced region. As a result, fine equiaxed grains are formed in the NZ of the DBL 2 configuration.

NZ-AS

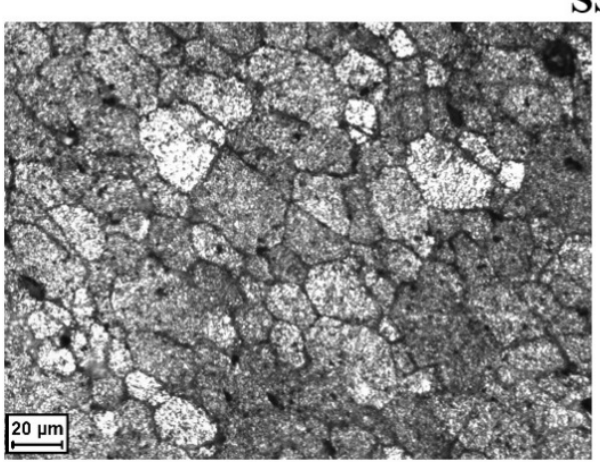

$14.23 \mu \mathrm{m}$

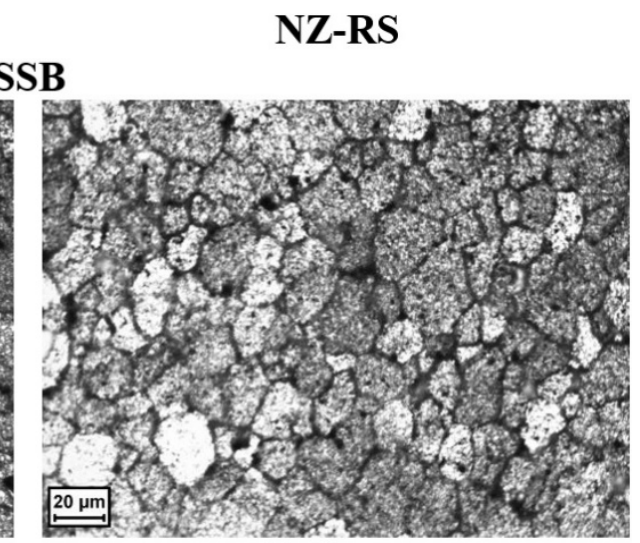

$13.59 \mu \mathrm{m}$

DBL1

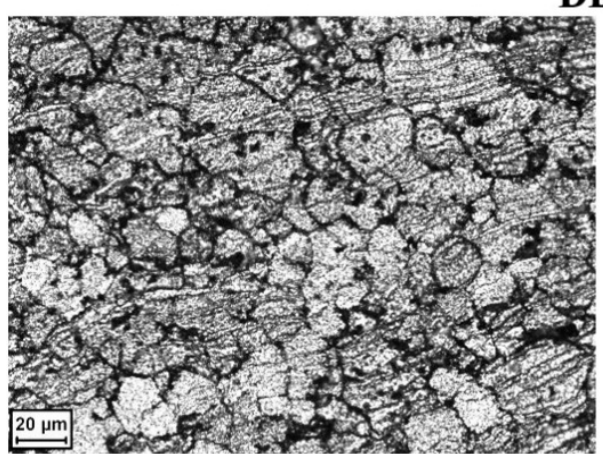

$15.26 \mu \mathrm{m}$

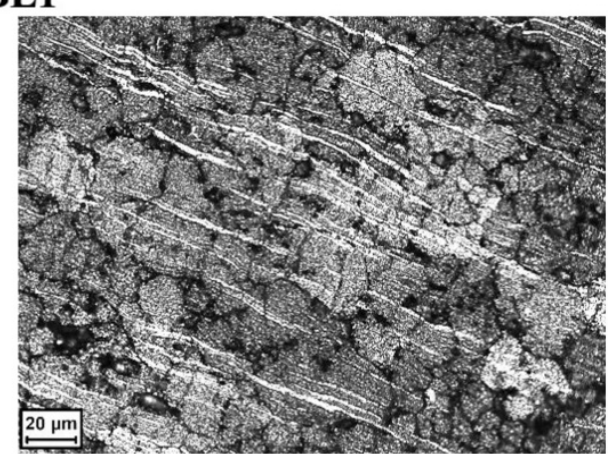

$14.65 \mu \mathrm{m}$

DBL2

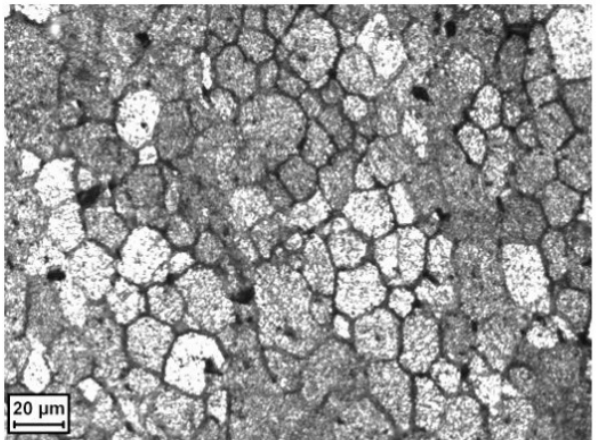

$14.42 \mu \mathrm{m}$

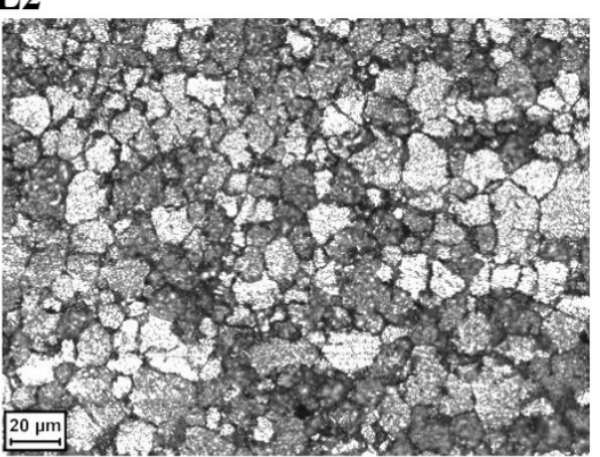

$13.84 \mu \mathrm{m}$

Figure 9. Metallographic images for the three different configurations in the advancing and retreating side of the NZ.

Figure 9 represents the grain structure and size of nugget grains in the AS and RS for the different joint configurations. All the grain structures resemble equiaxed grain as the nugget zone of the FSW encountered dynamic recrystallization [7]. However, a change in grain size can be observed between the retreating and advancing side. Aluminum alloys are susceptible to grain growth at higher heat exposure [14]. In the advancing side of the nugget, comparatively larger grains can be observed for all joint configurations compared to the RS. It is since AS of the nugget comes across higher heat input resulting in the attainment of increased peak temperature than RS (Figure 2). 


\subsection{Microhardness analysis}

Figure 10 shows the hardness distribution plot along the centerline for the three different joint configurations. The microhardness of the welded joints is a result of the combined effect of heat generation and plastic deformation of the material. From Figure 9 it can be seen that the microhardness value decreases along with the AS, reaches the lowest value in the HAZ and gradually increases to the highest value close to the base material. The reduction in microhardness value compared to the base material is because of the dissolution of the strengthening particles [20]. A similar trend can be seen in the RS also. This trend can be explained by the fact that the material in the nugget zone experiences severe plastic deformation due to pin stirring action. The stirring action is intense at the middle of the nugget and reduces away from the center of the nugget due to gradual reduction in the pin-workpiece interface. This causes refined grains in the middle of the nugget and a gradual increase in grain size away from the center of the nugget (Figures 8 and 9). The TMAZ is the region where both deformational and thermal aspects are comparatively less than nugget and the HAZ only comes across the effect due to heat. This generally results in a coarse elongated grain structure at HAZ and TMAZ [21]. This attributes to the lower values of microhardness away from the center of the nugget as well as in the TMAZ and HAZ. The highest value of microhardness is 81.3 $\mathrm{HV}_{0.1}$ in NZ and is obtained in the case of DBL 2 (Table 1), as finer grains exhibits higher hardness [14]. In the case of the DBL 2 configuration, as the UB is $1 \mathrm{~mm}$ offset in the RS, more amount of material is transported on either side resulting in excellent material mixing which leads to the generation of finer grains. This may be stated as the cause of the highest hardness for the DBL 2 configuration.

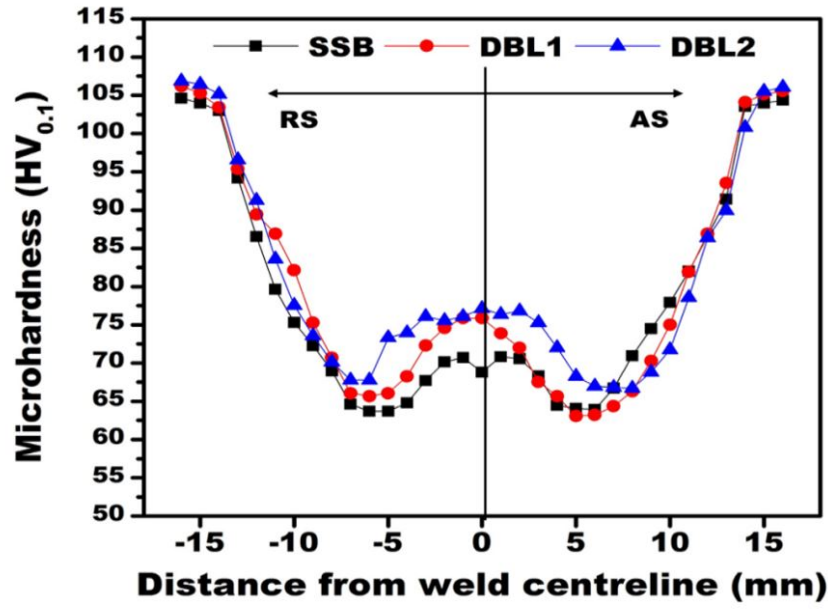

\begin{tabular}{|c|c|}
\hline \multirow[t]{2}{*}{ SSB } & $\begin{array}{r}\text { Mid. NZ-Top-11.12 } \mu \mathrm{m} \\
\text { Middle-10.55 } \mu \mathrm{m} \\
\text { Bottom-10.25 } \mu \mathrm{m}\end{array}$ \\
\hline & $\begin{array}{l}\text { AS- NZ-14.23 } \mu \mathrm{m} \\
\text { RS- NZ-13.59 } \mu \mathrm{m}\end{array}$ \\
\hline \multirow[t]{5}{*}{ DBL1 } & $\begin{array}{c}\text { Mid. NZ-Top-11.42 } \mu \mathrm{m} \\
\text { Middle-10.69 }\end{array}$ \\
\hline & Bottom-10.28 \\
\hline & $\mu \mathbf{m}$ \\
\hline & AS- NS-15.26 $\mu \mathrm{m}$ \\
\hline & RS- NS-14.65 $\mu \mathrm{m}$ \\
\hline \multirow[t]{3}{*}{ DBL 2} & $\begin{array}{c}\text { Mid. NZ-Top-9.7 } \mu \mathrm{m} \\
\text { Middle-9.12 }\end{array}$ \\
\hline & Bottom-8.62 \\
\hline & $\begin{array}{l}\mu \mathrm{m} \\
\text { AS- NZ-14.42 } \mu \mathrm{m} \\
\text { RS- NZ-13.84 } \mu \mathrm{m}\end{array}$ \\
\hline
\end{tabular}

Figure 10. Microhardness distribution plot along the weld centreline for the three different joint configurations.

\subsection{Tensile strength analysis}

The tensile properties of FSWed AA6061-T6 joints for different joint configurations in the transverse direction are evaluated (Figure 11). The test has been conducted to investigate the ultimate tensile strength (UTS), percentage elongation and joint efficiency $\left(\eta_{j}=U T S_{\text {joint }} / U T S_{B M} \times 100\right)$ of the joint formed by using DBL configuration joint and also to check the values with that of conventional SSB configured joint. Figure 10a shows the difference in the tensile plots of the weld joints formed with different weld joint configurations. Figure $10 \mathrm{~b}$ shows the variation of average values of result for UTS, \% elongation and joint efficiency of the welding formed using weld joint configuration with respect to that of SSB configured joint. From both the figures, a distinct effect of joint configuration on tensile properties can be ascertained. The value of UTS is $222 \mathrm{MPa}$, $237 \mathrm{MPa}$ and $242 \mathrm{MPa}$, \% elongation are 12.1, 14.8 and 13.9, and joint efficiency is 72.6, 76.6 and 78 for SSB, DBL1 and DBL2 respectively. It can be observed that with a reduction in the height of LB (vice versa for UB) the UTS of the DBL configured joint increases. An almost similar observation can be seen for percentage elongation also, DBL2 shows a slight reduction compared to DBL1. Figure $11 \mathrm{~b}$ also reveals that the joint efficiency of DBL1 and DBL2 is higher than that of SSB. It can be observed that similar to the microhardness as nugget grain size becomes finer the tensile properties are also increasing (Figure 8 and 9 ) as a finer grain size obstruct the dislocation movement due to increased grain boundary[22]. 

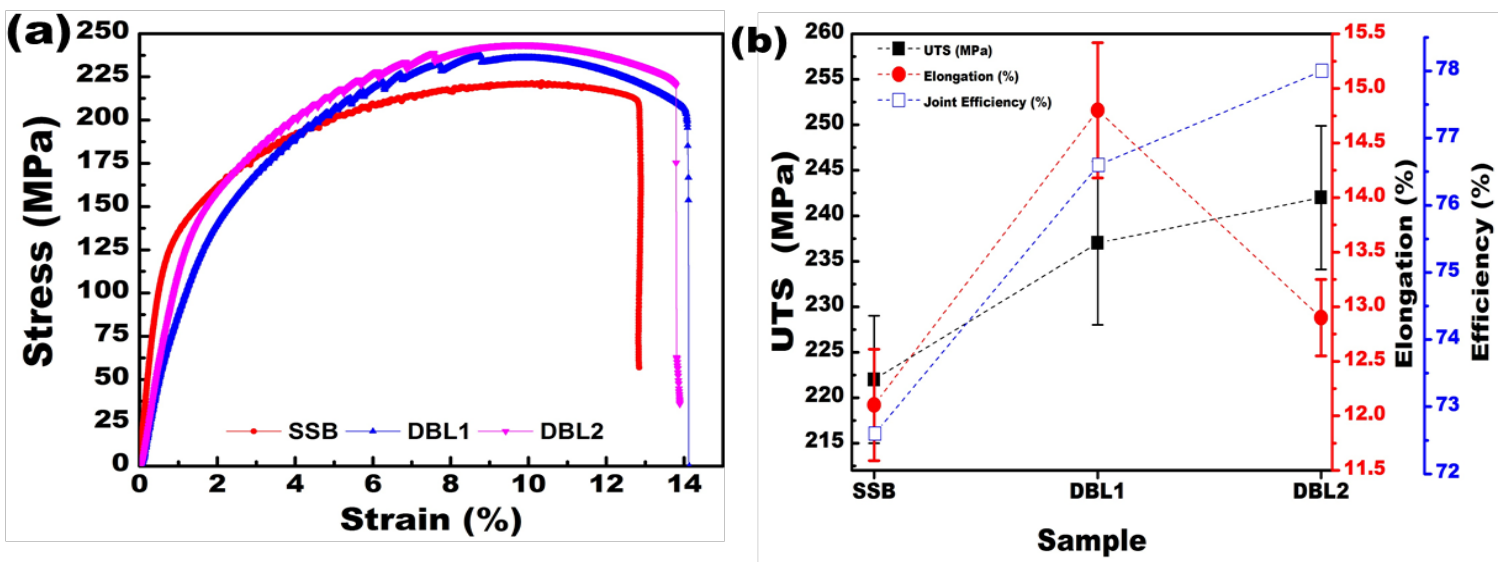

Figure 11. Comparison of the tensile strength, (a) comparison of the tensile plot for different types of welding and (b) Comparison of UTS, \% Elongation and joint efficiency of different DBL configured welded joint with SSB configured welded sample.

\subsection{Bend test analysis}

To evaluate and compare the bending strength of the FSWed joints formed at different joint configurations, three-point root bend tests of the welded samples were conducted. The result of the testing in terms of bend angle, maximum flexural strength and maximum flexural extension are shown in Table 3 for comparison purposes. The photographic image of the samples after testing is shown in Figure 12. The higher bending angle can be observed for the DBL configurations which can be attributed to a good metallurgical bonding of the material in the DBL joints. The maximum bend angle which has been attained by the samples is 151, 165 and 175 with SSB, DBL1 and DBL2 configurations respectively. It has been previously observed from the macrographs that the onion rings are very prominent on the lower side of joints especially for the DBL2 configuration. From this, it could be understood that a better material flow has been taken place at that particular region and thus higher bending angle is observed for DBL joints. For a similar reason, the maximum flexural strength was also obtained for the joints formed with DBL2 (643.1 MPa) joint configuration followed by SSB (642.4 MPa) and DBL1 (639.65 MPa). The particular finding is in good agreement with the tensile strength of the samples as it has been observed that the highest strength is attained by the joint formed with DBL2 joint configuration. However, almost a similar maximum extension within a range of 43.65-44.23 mm has been found for each case. The root bend test was carried out to check the presence of root defects in the weld joint line. Figure 11 evident the cracks or openings at the bending angle of $156^{\circ}, 165^{\circ}$ and $175^{\circ}$ for the joints prepared with SSB, DBL1 and DBL2 joint configuration respectively.

Table 3. Root bend testing data.

\begin{tabular}{cccc}
\hline Sample & Face bend angle () & Max. flexural stress (MPa) & Max. flexural extension (mm) \\
SSB & $151^{\circ}$ & 642.4 & 43.65 \\
DBL1 & $165^{\circ}$ & 639.65 & 44.23 \\
DBL2 & $175^{\circ}$ & 643.1 & 43.89 \\
\hline
\end{tabular}

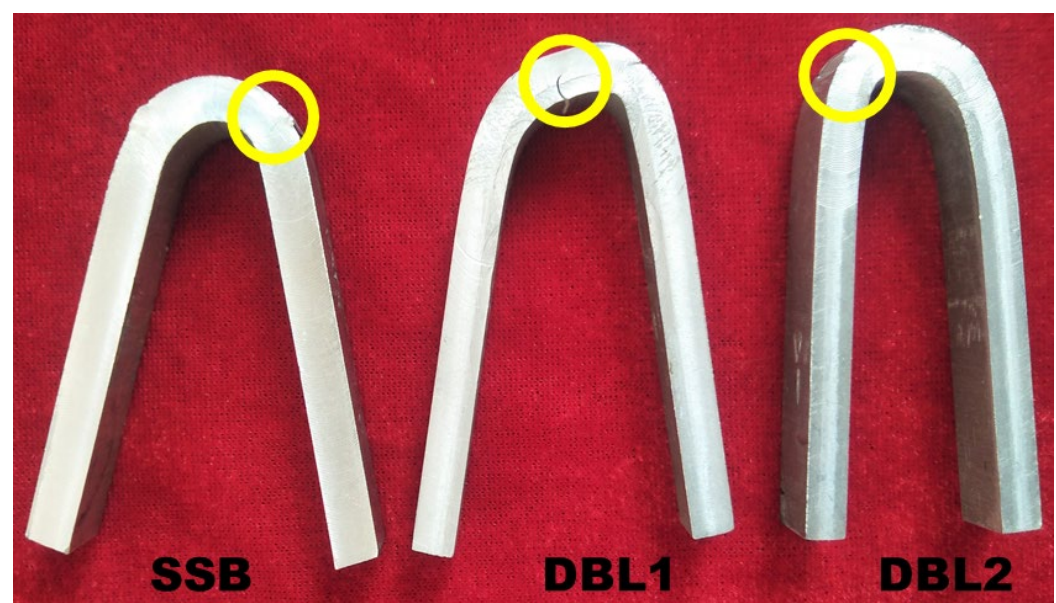

Figure 12. Macroscopic view of the root-bended welded sample 


\subsection{Fractography analysis}

Figure 13. shows the side and top view of tensile fractured samples along with its enlarged fractured section and its respective SEM fractographic morphology. The analysis of tensile fractured samples along with respective enlarged view reveals the effective variation of fracture location along with the morphology of fracture surface. The SEM image (fractography) reveals the variation in the mode of fracture for different samples. The observations from the tensile failure of the samples are enlisted in Table 4 in terms of fracture location, type of fracture and morphology of fracture surface as observed from Figure 13. for a clear understanding.

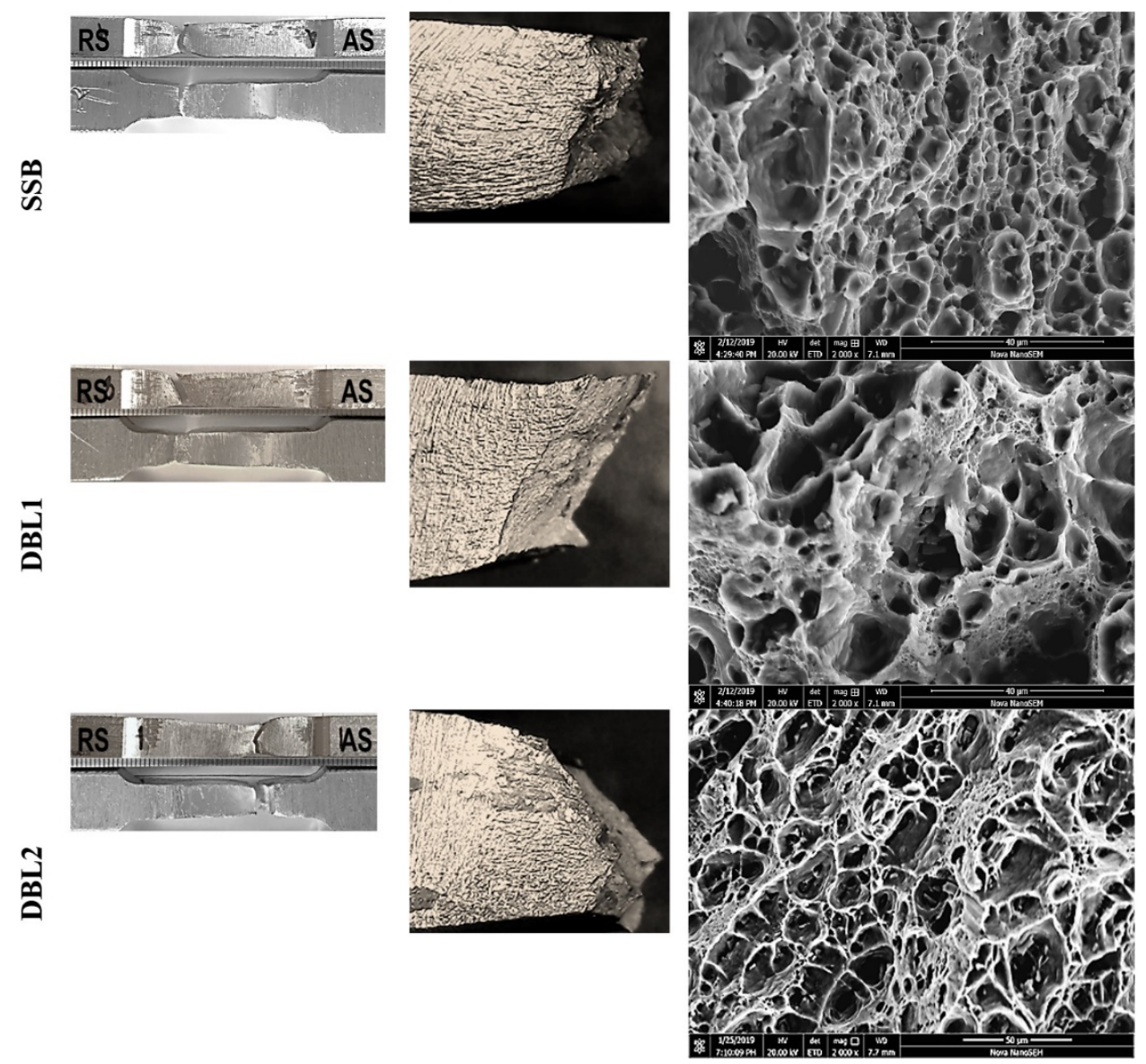

Figure 13. Fracture analysis of tensile fractured samples showing the different views of tensile fractured samples, close view of the fractured sample and the respective fractography.

Table 4. Variation in fracture type for the welding formed with a different joint configuration.

\begin{tabular}{cccc}
\hline Sample & Fracture location & Fracture surface morphology & Fracture mode \\
SSB & BM-RS & Dimples with flat surfaces & Mixed \\
\hline DBL1 & BM-RS & Dimples & Ductile \\
\hline DBL2 & TMAZ-AS & Fine dimples & Ductile \\
\hline
\end{tabular}

\section{Conclusions}

In the present investigation, an attempt has been made on the implication, compatibility and acceptability of modified DBL joint configuration in FSW over the existing SSB joint configuration. The key points and findings of the study are enlisted below:

- It has been observed from the analysis of the mechanism of metal movement analysis part that the material in the shoulder influenced region tends to drift from RS to the AS side. Comparatively the flow in DBL 2 configured joint is more complex in nature and this may help to form a sound weld.

- The analysis shows the formation of an onion ring in the pin influenced region, which indicates better material flow in that portion. Because of the better material flow, the chances of the formation of defects like root gap and kissing 
bond reduces. This point is also supported by root bend testing where no root flaw has been observed in DBL 2 configured joint. Whereas, the joint formed with the other two configurations show the same.

- In the case of tensile strength, a gross increase is obtained while considering a new joint configuration in comparison to the conventional one. The highest strength is observed for the DBL2 joint configuration which is $6.6 \%$ more than the conventional one.

- The bend testing reveals higher flexural strength for SSB and DBL2 configured joint. While DBL1 shows a bit lower value (639.65 MPa) compare to that of SSB type (641.35 MPa). The analysis reveals the increasing trend of bend angle from 146 to 157 for SSB-DBL2 respectively compare to S0 (145). The root bend test does not reveal any root opening or crack for any of the samples.

- The mechanical property of DBL configured joints indicates that the qualities of the joints formed by DBL 2 configuration are very much compatible with the joint formed with SSB type or even in some cases it shows higher values.

The above-mentioned points preliminary implies that the DBL joint configuration is very much compatible over conventional SSB configured joint in the field of FSW. The current investigation is carried out on a single parametric condition with a fixed UB: LB and LL length to make the study simple for the comparison. So, in the future some other critical studies can be carried out on this type of joint configuration by changing the parameters, UB: LB ratio and LL length to disclose the other aspects of this modified joint configuration in the field of FSW and hence open a new field on weld joint line configuration in FSW. Further, this joint configuration may also be tested for similar, dissimilar, composite and polymer joining.

\section{References}

[1] Thomas WM, Nicholas ED, Needham JC, Murch MG, Temple-Smith P, Dawes CJ. inventor. Friction stir butt welding. United States patent US PCT/GB92/02203. 1991 Dec 6.

[2] Singh G, Singh K, Singh J. Effect of process parameters on microstructure and mechanical properties in friction stir welding of aluminum alloy. Transactions of the Indian Institute of Metals. 2011;64(4-5):325-330. http://dx.doi.org/10.1007/s12666-011-0101-x.

[3] Gupta K. Advance manufacturing technologies - Modern machining, advance joining, sustainable manufacturing. Cham, Switzerland: Springer; 2017. http://dx.doi.org/10.1007/978-3-319-56099-1.

[4] Rajakumar S, Muralidharan C, Balasubramanian V. Establishing empirical relationships to predict grain size and tensile strength of friction stir welded AA 6061-T6 aluminium alloy joints. Transactions of Nonferrous Metals Society of China. 2010;20(10):1863-1872. http://dx.doi.org/10.1016/S1003-6326(09)60387-3.

[5] Mishra RS, Ma ZY. Frictions stir welding and processing. Materials Science and Engineering R Reports. 2005;50(1-2):1-78. http://dx.doi.org/10.1016/j.mser.2005.07.001.

[6] Rodriguez RI, Jordon JB, Allison PG, Rushing T, Garcia L. Microstructure and mechanical properties of dissimilar friction stir welding of 6061-to-7050 aluminum alloys. Materials \& Design. 2015;83:60-65. http://dx.doi.org/10.1016/j.matdes.2015.05.074.

[7] Banik A, Roy BS, Barma JD, Saha SC. An experimental investigation of torque and force generation for varying tool tilt angles and their effects on microstructure and mechanical properties: friction stir welding of AA 6061-T6. Journal of Manufacturing Processes. 2018;31:395-404. http://dx.doi.org/10.1016/j.jmapro.2017.11.030.

[8] Sato YS, Urata M, Kokawa H. Parameters controlling microstructure and hardness during friction-stir welding of precipitationhardenable aluminum alloy 6063. Metallurgical and Materials Transactions. A, Physical Metallurgy and Materials Science. 2002;33(3):625-635. http://dx.doi.org/10.1007/s11661-002-0124-3.

[9] Li B, Zhang Z, Shen Y, Hu W, Luo L. Dissimilar friction stir welding of Ti-6Al-4V alloy and aluminum alloy employing a modified butt joint configuration: influences of process variables on the weld interfaces and tensile properties. Materials \& amp. Design. 2014;53:838-848.

[10] Zhang W, Shen Y, Yan Y, Guo R. Dissimilar friction stir welding of 6061 Al to T2 pure Cu adopting tooth-shaped joint configuration: microstructure and mechanical properties. Materials Science and Engineering A. 2017;690:355-364. http://dx.doi.org/10.1016/j.msea.2017.02.091.

[11] Zhang Z, Li B, Feng $X$, Shen $Y$, Hu W. Friction-stir welding of titanium/aluminum dissimilar alloys: joint configuration design, as-welded interface characteristics and tensile properties. Proceedings of the Institution of Mechanical Engineers. Part B, Journal of Engineering Manufacture. 2014;228(11):1469-1480. http://dx.doi.org/10.1177/0954405413518514.

[12] Jayabalakrishnan D, Balasubramanian M. Friction Stir Welding of Dissimilar Butt Joints with Novel Joint Geometry. Acta Physica Polonica A. 2018;133(1):94-100. http://dx.doi.org/10.12693/APhysPolA.133.94.

[13] Goel P, Siddiquee A, Khan N, Hussain M, Khan Z, Abidi M, et al. Investigation on the effect of tool pin profiles on mechanical and microstructural properties of friction stir butt and scarf welded aluminium alloy 6063. Metals. 2018;8(1):74. http://dx.doi.org/10.3390/met8010074. 
[14] Banik, A., Barma, J. D., \& Saha, S. C. Effect of threaded pin tool for friction stir welding of AA6061-T6 at varying traverse speeds: torque and force analysis. Iranian Journal of Science and Technology, Transactions of Mechanical Engineering. 2019;44:1-16. https://doi.org/10.1007/s40997-019-00289-w.

[15] Silva ACF, De Backer J, Bolmsjö G. Temperature measurements during friction stir welding. International Journal of Advanced Manufacturing Technology. 2017;88(9-12):2899-2908. http://dx.doi.org/10.1007/s00170-016-9007-4.

[16] Husain MM, Sarkar R, Pal TK, Prabhu N, Ghosh M. Friction stir welding of steel: heat input, microstructure, and mechanical property corelation. Journal of Materials Engineering and Performance. 2015;24(9):3673-3683. http://dx.doi.org/10.1007/s11665-015-1652-5.

[17] Dialami N, Chiumenti M, Cervera M, de Saracibar CA, Ponthot JP. Material flow visualization in friction stir welding via particle tracing. International Journal of Material Forming. 2015;8(2):167-181. http://dx.doi.org/10.1007/s12289-013-1157-4.

[18] He X, Gu F, Ball A. A review of numerical analysis of friction stir welding. Progress in Materials Science. 2014;65:1-66. http://dx.doi.org/10.1016/j.pmatsci.2014.03.003.

[19] Acharya U, Roy BS, Saha SC. Effect of tool rotational speed on the particle distribution in friction stir welding of AA6092/17.5 SiCp-T6 composite plates and its consequences on the mechanical property of the joint. Defence Technology. 2019;16(2):381-391. https://doi.org/10.1016/j.dt.2019.08.017.

[20] Muthumanickam A, Gandham P, Dhenuvakonda S. Effect of friction stir welding parameters on mechanical properties and microstructure of AA2195 Al-Li alloy welds. Transactions of the Indian Institute of Metals. 2019;72(6):1557-1561. http://dx.doi.org/10.1007/s12666-019-01570-x.

[21] Liu F, Fu L, Chen H. Microstructure evolution and mechanical properties of high-speed friction stir welded aluminum alloy thin plate joints. Journal of Materials Engineering and Performance. 2018;27(7):3590-3599. http://dx.doi.org/10.1007/s11665-018-3441-4.

[22] Zhang L, Wang X. Microstructure evolution and properties of friction stir welding joint for 6082-T6 aluminum alloy. Materials Research. 2018;21(6). http://dx.doi.org/10.1590/1980-5373-mr-2018-0285. 